\title{
Re-Conceptualizing Developmental Areas of Assessment for Screening, Eligibility Determination and Program Planning in Early Intervention
}

\author{
Bonnie Keilty ${ }^{1, *}$, Patricia M. Blasco ${ }^{2}$ and Serra Acar $^{2}$ \\ ${ }^{1}$ Hunter College, City University of New York, 695 Park Avenue, 929 West Building, New York, NY 10065, \\ USA \\ ${ }^{2}$ The Research Institute, Western Oregon University, 345 N. Monmouth Avenue, Monmouth, OR 97361, USA
}

\begin{abstract}
Contemporary recommended practices in early childhood assessment strive to gain a holistic picture of child learning and development to inform screening, eligibility, and program planning decisions. These practices have traditionally focused on competencies reflected in developmental domains with limited attention to the approaches-tolearning used to acquire those competencies. In this article, we call for the examination of early childhood constructs that impact a child's ability to learn and develop, such as executive function (EF), mastery motivation, self-regulation and selfdetermination, specifically in the infant-toddler period. With EF defined as a wide range of central control processes in the brain that link and categorize information that is discernible in cognitive, motor, and behavioral responses [1], we propose a model of EF as the core construct that drives and unites these learning processes and describe how the model can be applied to Part C early intervention screening, assessment, eligibility determination, and program planning, as well as identify future directions in research and personnel preparation.
\end{abstract}

Keywords: Assessment, early intervention, approaches-to-learning, executive function, eligibility, program planning.

Developmental researchers, early childhood education leaders, and families are paying significant attention to children's approaches-to-learning as critical processes used to acquire new competencies and impact future learning [2]. These processes consider the attentional, organizational, regulatory, and motivational components necessary for learning. As researcher efforts continue to operationalize what these processes look like in the early years and how they impact learning, their findings are being translated into practices supporting children's acquisition of skills that lead to learning across components. Despite this attention, early intervention (EI) programs under Part C of the Individuals with Disabilities Education Improvement Act (IDEIA) [3] for infants and toddlers with or at risk for developmental delays or disabilities continue to primarily focus developmental assessments on competencies traditionally reflected in developmental domains.

Although domain-based skills and abilities reflect an essential component of child development, neglecting or minimizing the role approaches-to-learning have on child functioning can result in an incomplete developmental profile obtained during assessment procedures. Pediatricians (as referral sources) and EI evaluators such as therapists and infant specialists

*Address correspondence to this author at the Hunter College, City University of New York, 695 Park Avenue, 929 West Building, New York, NY 10065, USA;

Tel: 212-772-4709; Fax: 212-650-3542; E-mail: bkeilty@hunter.cuny.edu often utilize developmental tests on young children that can miss developmental needs due to the lack of specificity inherent in early childhood instruments $[4,5]$. Thus, decisions around El referral, eligibility, and program planning are made with inadequate data. This may result in children not receiving El services that may be beneficial, or receiving services that only attend to part of the developmental picture. Including approaches-to-learning in assessment procedures assures El decisions are based not only on what the child knows and can do, reflected in developmental domains, but also how the child approaches opportunities to learn new knowledge and skills and how they process that information into problem-solving and behavioral skill development.

In the Developmental Systems Approach (DSA) to early childhood intervention, Guralnick [6] described child functioning as the transaction of developmental resources (i.e., domains of functioning), and organizational processes that comprise those skills and abilities needed for goal-directed behavior (i.e., approaches-to-learning). These child contributions are just one aspect of the larger DSA model that considers the entire family microsystem. El services can play a role in influencing child development by attending to and working within that microsystem.

The purpose of this article is to expand on Guralnick's [6] call to align El practices to the contemporary developmental science evidence-base 
by focusing on approaches-to-learning, specifically in the infant-toddler period. We propose a conceptual model of approaches-to-learning, under the core construct of executive function (EF), and describe how the model can be applied in El assessment processes and subsequent decisions during screening, eligibility determination, and program planning.

\section{AN INTEGRATED MODEL OF EXECUTIVE FUNCTION}

In our model, we posit that the various processes usually described as approaches-to-learning can be integrated under the construct of EF. These processes include mastery motivation (e.g., applying goal-directed behaviors), self-regulation (e.g., coping with external and internal stimuli), and self-determination (e.g., making a plan, making a choice). All of these components are life-long skills that begin in the early childhood period and therefore are important areas to assess and provide intervention as early as possible.

\section{Executive Function}

EF is regulated by complex systems of interrelated neural networks [7], especially the prefrontal cortex part of the brain [1]. These neural network processes direct, connect, and organize information resulting in planned behavior, such as emotional control, inhibition, working memory, goal selection, and organization [8]. EF describes the processes related to and that motivate goal-directed behavior [9, 10]. Researchers have studied young children between 3 and 6 years of age who demonstrate skills representative of $E F$ including working memory, self-regulation, attention, and inhibition [11]. Assel, et al. [12] found that EF skills and visual-spatial skills of typically developing children were stable across 3, 4 and 6 years of age. In addition, visual-spatial and EF skills at 6 years old were related to greater mathematical skills at 8 years old. Although a number of studies have found early deficits in visualspatial abilities in children who had later math learning disabilities [13], the Assel study is unique because the authors examined the relationship between visualspatial skills and EF skills. The importance of understanding at an early age how to plan and organize actions, maintain attention to tasks, and recall past experience to apply to new experience are all processes identified as deficits for children with learning disabilities (LD) as well as with AttentionDeficit/Hyperactivity Disorder (ADHD) [14]. The capacity to plan and sequence behaviors to achieve tasks is a major component of EF that influences later math and reading abilities at school age [15].

The beginnings of EF skills can be seen within the first year of life [1]. For example, working memory refers to the process of recalling relevant task information to guide future behaviors [16]. Researchers found evidence of working and implicit memory in the infant years, such as when the parent says peek-a-boo, the child raises her hands to cover her face [17]. Observing and measuring EF in the first three years of life can make important contributions in assessing populations who are vulnerable to developmental delay.

Young children often demonstrate EF through structured tasks to achieve a specific goal [18]. This could be as simple as learning to push the lever to make a toy pop up. Lawson and Ruff [19] used measures of focused attention with infants to assess the infant's learning behavior and predict later cognitive ability. These researchers believed that an infant's focused attention could be observed during active exploration of play objects. When a young infant is presented with a novel object, she will explore the toy using sensory input by mouthing, shaking and visually exploring the object. When the item loses its novel appeal, she may drop it or engage in repetitive behavior with the object with less concentration on the object. For a 14 month-old, focused attention might be demonstrated by both visually attending and labored breathing while completing a challenging task. More casual looking or attending does not show these systematic changes in relation to novelty [19]. Higher levels of focused attention in infancy have been linked to higher scores on later tests of intelligence [19].

Researchers pointed out that EF is a multifaceted construct and not a series of isolated skills [20]. In typically developing children, research shows that executive functioning is linked to problem-solving across cognitive and social/emotional domains [21]. The development of social skills and the ability to understand the appropriateness of social behavior across environments continues to be an issue for young children who are considered at-risk [22]. For many children at-risk due to environmental and biological reasons such as low birthweight (LBW) and prematurity, these behaviors are not easily learned and generalized to social environments. The EI team can assess young children by interpreting children's learning experiences and creating a program plan that scaffolds those experiences. In the long run, this will 
help the individual child reorganize and regulate behavior and avoid challenging or negative behavior $[23,24]$.

\section{Measurement of EF}

As stated previously, EF skills are tantamount to success for academic achievement and in later life [25]. Deficits in EF have been found to be associated with a number of childhood disabilities including ADHD; attention and inhibition concerns, LD, cognitive flexibility and working memory, and behavior disorders (social skills, self-regulation) [26]. Each of these disabilities impact school performance, and later, may affect independent adult life skills. Therefore it is critical that EF be observed, measured and promoted as early as possible in children with or at risk for developmental delay who are referred to or receive services in El.

Most EF measures were developed for school-age children. However, Wiebe, Espy, and Charak [27] used statistical analyses, in one case confirmatory factor analysis, to see if some items of working memory and inhibition could be adapted for preschool-age children. Other researchers administered single tasks such as Piagetian "A not B task" known to reflect competencies in object permanence. In this task, the child retrieves a hidden object from one side or barrier (A cloth) and then transfers that knowledge to the task when the object is hidden in a second location (B cloth) [28]. The direction (correct vs. incorrect) towards which the infant reaches in this reversal trial is the essential measurement of the A-not-B trial [21]. This task has been modified for children up to 24 months.

Although traditional early childhood assessments do not typically address EF, items on these instruments represent components of EF. The Woodcock Johnson III: Test of Cognitive Abilities and the Behavior Rating Inventory of Executive Functioning measure components of EF in children as young as 2 years of age [26]. In the Bayley Scales of Infant Development III (BSID III) [29], three cognitive items test the "A not B task": Item 40, "Finds bracelet by looking first under correct washcloth when hidden on both left and right sides"; Item 45, "Finds bracelet by looking first under correct washcloth when hidden both left and right sides (reversed)"; Item 50, "Finds bracelet by looking first under correct washcloth when hidden on both left and right sides (visible displacement)". In one study, Lowe, Erickson, MacLean, and Duvall [30] found that babies born full term were 4.6 times more likely to achieve object permanence on these tasks than children who were born low birth weight. In another study of low birth weight infants, they found that girls did better than boys on object permanence tasks [31]. Given this risk of EF development in infants and toddlers with developmental delays or disabilities, El assessment should focus on EF in both determining the need for services via eligibility processes and planning developmental programs that target EF as well as domain-based outcomes.

Both the BSID III and the Woodcock-Johnson are standardized instruments, which alone cannot be used for determining El eligibility nor represent the child's functioning in everyday life required for program planning. The Behavior Rating Inventory of Executive Function, Preschool Version (BRIEF-P) [16] is the first norm-referenced rating scale designed to measure EF in toddlers and preschool children (ages 2 to 6 years). The $B R I E F-P$ is completed by parents or caregivers to rate a child's EF within the context of his or her daily environments. The BRIEF-P consists of 63 items that measure various aspects of executive functioning including: Inhibit, Emotional Control, Plan/Organize, Shift, and Working Memory. Normative data are based on ratings of children, aged 2.0 through 5.11 years, from 460 parents and 302 teachers from urban, suburban, and rural areas, reflecting U.S. Census estimates for race/ethnicity, gender, socioeconomic status, and age. Clinical samples included children in the following groups: ADHD, prematurity, language disorders, autism spectrum disorders, and mixed clinical.

The $B R I E F-P$ can be administered with parents and caregivers by trained professionals who have backgrounds in psychology and related services. Gioia and colleagues [16] reported internal consistency (Cronbach's $\alpha$ ) for parent ratings on the BRIEF-P scales and total score. These include: Inhibit $\alpha=.90$, Shift $\alpha=.85$, Emotional Control $\alpha=.86$, Working Memory $\alpha=.88$, Plan/Organize $\alpha=.80$, and Global Executive Composite $\alpha=.97$. Pearson correlations were used to examine stability of parents and teachers' ratings on the BRIEF-P over an average of 4 weeks (range 1 to 9 weeks). Correlations ranged from .78 to .94 with the lowest on the Plan/Organize (parents) scale and the highest on the Inhibit (teachers) scale. Validity studies were conducted using factor analysis with other preschool rating scales. Results supported the index structure of the BRIEF-P scales which correlated with the other measures [32].

El practitioners can use the BRIEF-P when assessing toddlers to include EF in assessment 
decisions. Across the entire birth to three age range, EI practitioners can examine their current assessment instruments for items that reflect early EF competencies that, combined with naturalistic observations of EF, can inform a comprehensive picture of the child's development considering both domain-based skills and approaches-to-learning.

\section{Mastery Motivation}

Mastery motivation is defined as "a psychological force that stimulates an individual to attempt independently, in a focused and persistent manner, to solve a problem or master a skill or task which is at least moderately challenging for him or her" [33(p319)]. The motivation to master is reflected in a child's goaldirected behaviors toward an object (e.g., completing a puzzle), person (e.g., influencing another's behavior), or motoric skill (e.g., learning to walk) [34, 35]. As such, mastery motivation is usually operationalized as persistence, as well as the affective components of enjoyment and lack of frustration in goal pursuit. The interrelatedness of mastery motivation to other EF constructs is clear when "what it takes" to demonstrate goal-directed persistence in unpacked. Mastery motivation is the impetus propelling the child to attend, keep a goal in mind, and use various problem solving strategies - all EF competencies. Mastery motivation contributes to a child's approach to learn by inciting and maintaining behaviors focused toward goal achievement.

Mastery motivation is maximized when the goal to be achieved is scaffolded within the child's individual zone of proximal development [34, 36]. For children with potential developmental delays or disabilities, assuring an individual moderate challenge requires assessing the characteristics of the task based on the child's abilities. Using these assessment data, the social and physical learning environment can be adapted to provide moderate challenges that are neither too easy, resulting in nothing to master, nor too hard, resulting in cursory or failed attempts.

Research has found infant-toddler mastery motivation to be related to future competence. In a seminal study on mastery motivation, Messer and colleagues [37] found infant mastery motivation to be a better predictor of early preschool cognition than infant developmental scores. A more recent study found maternal ratings of persistence at 2 years to be related to cognition and literacy achievement at 8 years, but only for girls [38]. Including mastery motivation in assessment could contribute to El eligibility and program planning decisions.

In research studies, the most frequently used approaches to assess mastery motivation is observation during a structured task and a parentcompleted questionnaire, the Dimensions of Mastery Questionnaire (DMQ 18) [39]. Structured tasks are designed to elicit object-related mastery motivation by providing individual, moderately challenging tasks and measuring persistence and affect. The usability of this approach to El assessment practices is limited since the tasks are contrived as opposed to naturalistic opportunities. Authentic assessment approaches are recommended in El so that the data gathered directly link to a child's everyday developmental functioning [40]. These structured mastery motivation tasks also solely measure object mastery motivation, omitting social and gross motor mastery motivation competencies. The $D M Q$ is a parent-completed measure that provides a more comprehensive mastery motivation picture by assessing object, social (with children and adults), and motor persistence, as well as affective responses of pleasure and frustration [41]. Morgan and colleagues [41] reported adequate stability over the infant-toddler years, with scores increasing as the child ages, reflecting developmental growth over time. While concerns about whether the $D M Q$ is measuring parent perception versus actual mastery motivation have been raised [41], family members can provide valid and reliable ratings of their child's learning and development when adequately supported [42]. With no cut scores or quantitative measures of "delay" for mastery motivation at this time, professionals and family members can collaborate, using the $D M Q$ as a guide, to qualitatively understand the child's mastery motivation as it contributes to the child's approachesto-learning.

Through parent report, the $D M Q$ can be used to gather authentic data on a child's mastery motivation that may be difficult to obtain through naturalistic observations. Busch-Rossnagel and Morgan [34] report that observing a sufficient level of naturally occurring mastery motivation can be difficult as these behaviors occur at low frequencies in everyday life, most particularly in the infant/toddler period. However, while assessors are conducting authentic developmental assessments, they can be aware and take note of mastery motivation behaviors as they naturally occur when moderate challenges do arise.

Mastery motivation is evident in some early childhood assessment instruments, although not a 
significant component. For example, the criterionreferenced Transdisciplinary Play-based Assessment (TPBA) [43] includes achievement motivation as an area to assess under the Emotional and Social domain, within the sense of self subdomain. This area asks about persistence, pride, and frustration with challenges, across social interactions, play skills, and self-help skills. Recently, Morgan and colleagues [41] have begun to study the link between self-regulation and mastery motivation.

\section{Self-Regulation}

Self-regulation is defined as "the way in which children process and respond to input or stimuli received from their environment through the management or control over their emotions, behavior, and attention" [44(p41-42)]. Children learn to regulate their emotional responses, physiological states, sensory processes and motor planning, and cognitive organization for learning. In the earliest stages, infants rely on external regulation by their caregivers. As the child grows, he or she child takes on more of the regulatory responsibility [18].

Emotional and cognitive regulatory capacities are inherent in the EF components of working memory, inhibitory control, and mental flexibility, and therefore are directly related to learning. These include the ability to establish emotional control of their environment and to plan and organize their behavior [41]. In the young child, self-regulation and the ability to engage in goaloriented problem-solving tasks are related to later EF skills $[18,41]$. The ability for the young child to sustain attention and to plan and organize his or her actions is critical for later academic skills.

Ursache and colleagues [45] found that emotional reactivity and emotional regulation interacted at 15 months to predict executive functioning at 4 years. Blair and Raver [46] argue that self-regulation and domainbased competencies transact, with adults maximizing child learning by simultaneously attending to and building on the child's self-regulatory abilities and domain-based competencies. Evidence of this can be seen in Vallotton and Ayoub's [47] study where toddler's language and regulatory competencies were related. A toddler can use his or her language competencies to help regulate behavioral responses while, at the same time, a child's ability to regulate helps ready the child to attend and organize in order to learn new competencies. While less of a focus in the typically developing literature, sensory processing, physiological regulation, and motor planning are potential areas of concern for children with or at risk for developmental delays or disabilities. Assessing these foundational skills can contribute to understanding the child's readiness to attend to and engage in learning opportunities.

In El, self-regulation is assessed through specific items on comprehensive developmental instruments or separate instruments specifically focused on selfregulation. The norm-referenced Developmental Assessment for Young Children, $2^{\text {nd }}$ Edition (DAYC-2) [48] is widely used in El eligibility procedures. Selfregulation items on the $D A Y C-2$ are included in the Social or Emotional (e.g., Item 10: "Comforts self") and Cognitive (e.g., Item 30: "Manages 3-4 toys by setting one aside when given a new toy") domains. The TPBA [43] includes sections on motor planning and modulation of senses in the Sensorimotor domain, regulation of emotions and behavioral regulation sections in the Emotional and Social domain, and attention, memory, and problem solving sections in the Cognitive domain. On both these instruments, there is no separate self-regulation score derived. However, assessment of these items can provide qualitative data on the child's self-regulatory competencies. The Sensory Profile - 2 [49] and the Temperament and Atypical Behavior Scale (TABS) [50] are both parentcompleted, self-regulation measures, focused particularly on sensory processing, with the TABS including emotional regulation aspects. These instruments provide scores and developmental profiles of strengths and concerns specific to the child's selfregulatory abilities that can contribute to identifying a child's need for El supports, as well as planning developmental programs for eligible children.

\section{Self-Determination}

The concept of self-determination is rapidly gaining attention in the field of early intervention/early childhood special education (El/ECSE). In early childhood, Blasco, Falco, and Munson [51] identified skills foundational to self-determination to:

include self-awareness (understanding of being separate from caregiver), selfknowledge (understanding their own feeling states and recognizing them in pictures), self-evaluation (estimating the quality of their performance relative to others), choice-making (expressing preferences verbally or nonverbally), 
meta-representation (identifying others' emotional states, simple understanding of intention, memory, feelings, and images), and goal setting and attainment (persisting at tasks, also known as mastery motivation) [(p. 64.)].

According to Erwin and colleagues [52], selfdetermination has three main components a) choice making and sharing individual likes and dislikes, b) independence, and c) having an effect on objects and others. The concept of self-determination is dynamic and influenced by the opportunities afforded in a child's natural environment. Young children develop selfdetermination skills through the influence, encouragement, and guidance of family members [51].

Erwin and Brown [53] developed a set of selfmonitoring questions to support practitioners and families in assessing self-determination across early childhood routines. These questions guide users to identify opportunities and obstacles for promoting selfdetermination in young children with and without special needs during routine activities. Moreover, Erwin et al. [52] provided a list of strategies including questions, such as "Can your child reach a variety of playthings by himself or herself?" and "Is your child encouraged to express a range of emotions?" [(p33)] The authors suggest that practitioners use the questions as a checklist to then create strategies a family can use to promote self-determination in their home setting. These questions and the competencies reflective of early self-determination can be used in EI assessment to understand both the child's current selfdetermination skills and the opportunities afforded in the family's cultural context.

As evidenced above, there is clearly an overlap or relationship between the constructs of EF, mastery motivation, self-regulation, and self-determination. Since EF is comprised of the cognitive processes that motivate the brain to action and behavior, EF can be considered the core construct that interacts with the other constructs. Figure 1 illustrates this relationship. Using the atom as a metaphor, EF is the nucleus that drives a child's approaches-to-learning, recognizing the interconnections of mastery motivation, self-regulation, and self-determination. This metaphor also demonstrates the neural networks that are actively directing interactions and behaviors in the developing brain. The Integrated Model of EF can be used as a framework for considering these approaches-tolearning processes in El assessment decisions.

\section{APPLYING THE EF MODEL TO EARLY INTERVENTION ASSESSMENT DECISIONS}

The Integrated Model of EF is comprised of attentional, organizational, motivational, and regulatory processes important to learning. Including these

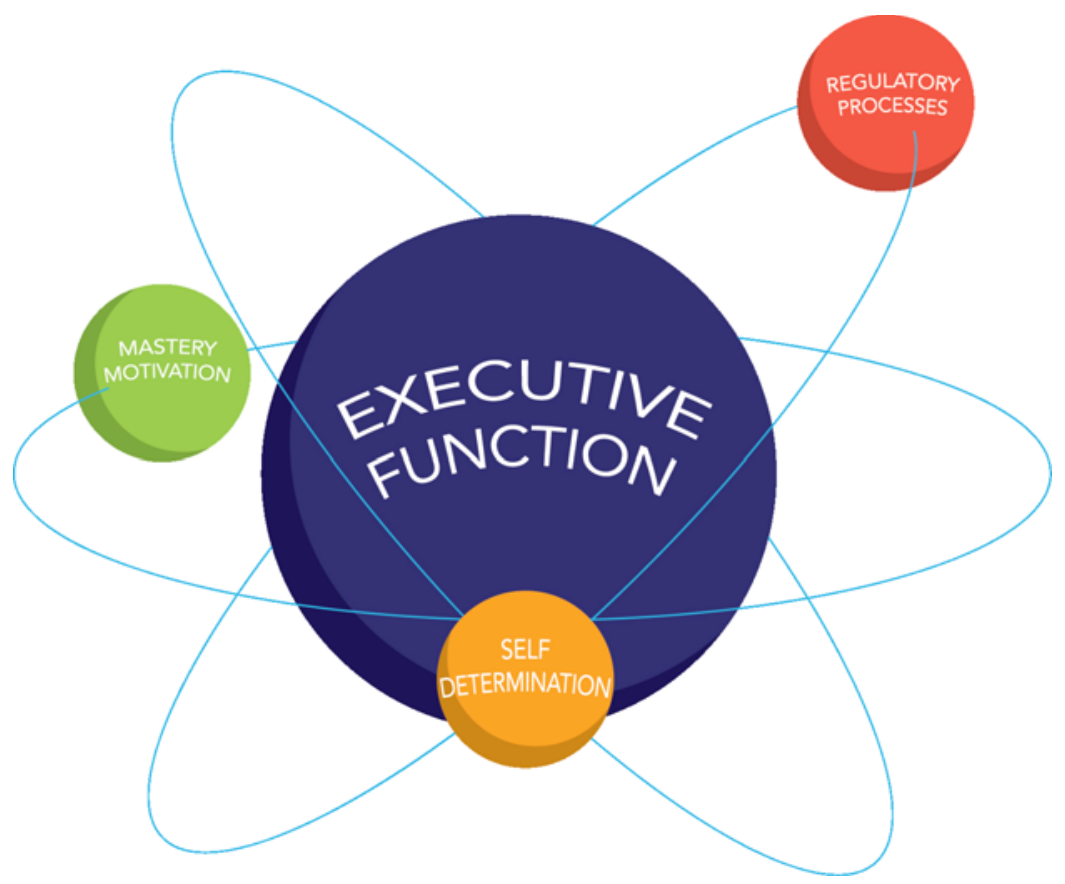

Figure 1: An Integrated Model of Executive Function (EF).

This figure illustrates early childhood constructs that impact EF (Enright, Blasco \& Keilty, 2015). 
processes as areas for assessment can contribute to the creation of a more complete picture of the child's developmental strengths and needs to inform conclusions and resulting recommendations drawn from assessment data. As described above, there is a dearth of fully developed assessment instruments and processes focused on young children's approaches-tolearning [6]. While evidence-based instruments and processes specific to assessing EF in infants and toddlers are needed, approaches-to-learning can begin to be integrated into El assessment processes to be better aligned with contemporary developmental science. Table 1 outlines potential questions assessors can use to examine and make inferences about a child's strengths and needs applying the Integrated Model of EF. This information can be gathered and validated through parent report, observations and assessments.

Assessments provide the data for making informed decisions on (a) referring for further evaluation (screening), (b) determining El eligibility (evaluation), and (c) outlining individual outcomes, supports, and strategies to promote child learning and development (program planning). Current recommended practices endorse assessment processes and decision making that utilize informed clinical opinion, integrate development into functional outcomes, and assess authentically within natural environments. While these practices have focused primarily on developmental competencies, these same practices can be applied to embed EF constructs into assessment processes and decisions.

\section{Informed Clinical Opinion}

El eligibility criteria varies greatly across states, with most specifying a delay of either a specific percentage or standard deviation in one or more domains of development (i.e., cognition, communication, motor, social-emotional, and adaptive) as part of its eligibility definition. However, assessment scores are limited in their representation of a child's full developmental profile and often do not measure more subtle and other qualitative aspects of development that could warrant EI eligibility. In recognition of this, U.S. federal EI regulations require that eligibility decisions use "informed clinical opinion" in conjunction with scores on assessment instruments [54]. Informed clinical opinion is used to make "a determination regarding difficult-tomeasure aspects of current developmental status and the potential need for early intervention" [55(p1)]. At this point, EF constructs can be considered "difficult-tomeasure" due to the limited assessment guidance available. Additionally, EF can be impacted by environmental factors including high risk family situations such as poverty, lack of parental education and interaction and substance abuse. Dannemiller [56] used data from the NICHD Study of Early Child Care and found not only that family environment predicted children's ability to regulate their attention by the preschool years but also that attention processes, in turn, predicted achievement, language, and social outcomes for these children. El assessors can gather objective data on a child's EF as well as environmental risks to EF development which can contribute to a holistic picture of child learning and development,

\section{Table 1:}

\section{Questions to Consider in the Integrated Model of Executive Function}

1. How well can the child focus on and maintain attention to a task?

a. Can the child shift attention from person/object or task to another?

2. What working memory skills are evidenced through the child's spontaneous actions and communications (verbal and non-verbal)?

a. Can the child recall persons/objects, action sequences (e.g pat-a-cake), concepts or events?

3. How easily is the child able to regulate (control) emotional states?

a. How easily is the child able to self-calm when emotions become intense?

b. How well is the child able to inhibit impulsive actions and emotions (e.g., physical, vocal, or verbal outbursts) in order to attend to persons/tasks?

4. How well can the child regulate responses to sensory experiences? What effect do sensory experiences have on the child's emotional responses?

5. How does the child regulate their physical and physiological responses to sensory experiences?

6. What effect do sensory experiences have on the child's attention?

7. Does the child persist when working on a challenging task (persons/objects)?

a. Does the child show pleasure in attempting or completing a task? 
integrated with knowledge of a child's current skills and abilities.

The EF constructs provide qualitative data on a child's approaches-to-learning that can be used in eligibility determination via informed clinical opinion. EI aims to intervene as early as possible to ameliorate the effects of developmental delays or disability. However, a national sample of El participants found the average age of full El enrollment (i.e., development of the Individualized Family Service Plan) for children eligible due to a developmental delay was 20 months, leaving only 16 months for program participation [57]. Currently, the percentage of infants under 12 months served in the United States is $1.11 \%$, while $2.67 \%$ and $4.66 \%$ of the population are served between 12 and 24 months and 24 and 36 months, respectively [58]. Attending to EF constructs during eligibility using informed clinical opinion may indicate the need for El earlier than traditional quantitative scores on developmental instruments.

Decisions based on informed clinical opinion need to be situated in objective data informed by the early childhood evidence base rather than subjective impressions [59]. El assessors can apply the EF research and current tools identified above, converge the resulting findings with other supporting documentation, to guide the use of one's judgement in making informed eligibility decisions. This can occur while recognizing that research is still needed on the best authentic tools and processes, already designed or needed to be developed, to inform eligibility decisions that consider EF [5].

\section{Child Functioning}

The El and early childhood special education field recognizes the limitations of looking at child development by developmental domains. Children actually apply their competencies across domains as they express what they know and can do in everyday life. Therefore, the field recommends focusing on these functional abilities that are meaningful to everyday participation and learning $[4,5]$. In 2003, the U.S. Office of Special Education Programs funded the Early Childhood Outcomes (ECO) Center, charged partly with identifying expected outcomes, or intended results of child and family participation in El and preschool special education programs [60]. Through a series of stakeholder feedback, the ECO Center identified three child outcomes purposely designed to cross developmental domains and be functional in nature
[60]. These outcomes are: (1) Children have positive social relationships; (2) Children acquire and use knowledge and skills; and (3) Children take appropriate action to meet their needs [60(p8)]. EF processes are inherent in the acquisition of learning skills to meet each of these outcomes and explicit to acquiring and using knowledge and skills. El assessors can examine how the child's current EF processes contribute to the child's present level of functioning, which can inform the creation of outcomes and strategies to meet those outcomes that target EF processes.

Similar to domain competencies, assessment findings around EF must be situated within the cultural context of the family and subsequent learning opportunities afforded. For example, families of different cultures may focus on different aspects of mastery motivation [61]. While beyond the scope of this article, especially given the lack of research on cultural variations in the $\mathrm{EF}$ literature, attending to the role of the authentic environment to infant-toddler functioning and competence is critical to quality assessment practices.

\section{Authentic Assessment Methods}

Authentic assessment methods are recommended practices in early childhood [40]. Assessing "authentically" occurs via multiple observations of child functioning in everyday contexts and discussions with parents and other caregivers who witness this functioning more than any evaluator ever could. EI assessors understand the child's developmental and learning processes by replacing discrete tasks on standardized instruments with cross-domain competencies, in consideration of environmental factors and cultural expectations. Authentic assessment approaches provide applicable and relevant information based on data collected through observations, anecdotal records, and parental reports. Observations of multiple samples of behaviors over time result in descriptive data of the child's strengths and needs.

Authentic assessment findings reflect children's development and learning in routine activities. The primary purpose of authentic assessment is to guide and support children's learning [62]. Bagnato, McLean, Macy, and Neisworth [63] define authentic assessment as "ongoing observations and documentation in everyday settings and routines to identify functional capabilities and needs" [(p246)]. According to Division for Early Childhood's (DEC) white paper on "Promoting 
Positive Outcomes for Children with Disabilities: Recommendations for Curriculum, Assessment, and Program Evaluation" one of the critical attributes of high-quality assessment is authentic assessment [64].

Using authentic assessment has several benefits. First, it provides data on a large number of behaviors across child functioning. This approach recognizes that developmental domains and approaches-to-learning are interwoven and affect each other. Secondly, authentic assessment integrates family concerns and thoughts. Therefore, following an authentic assessment approach may expedite reciprocal dialogues between El practitioners and families. Moreover, authentic assessment approaches acknowledge the child's competencies across multiple occasions with various partners, objects and materials. Conducting systematic observations of the child within the context of play, social interactions, and routine activities may be used to develop outcomes during the Individual Family Service Plan process. El assessors can utilize authentic assessment procedures to examine children's approaches-to-learning within their everyday, functional contexts.

\section{FUTURE DIRECTIONS}

The Integrated Model of EF described above illustrates the importance of each of the approaches-tolearning components to a child's overall competence, as well as their interrelatedness. Research and specific practices related to approaches-to-learning in infants and toddlers is still emerging. The following identifies areas for future research that can inform El practices in assessment and intervention.

Designing and testing authentic instruments and other tools to guide El assessment decisions is clearly needed. Significant attention to assessing EF is occurring with preschool children. For example, EF Touch [65] is a computerized assessment that includes tasks appropriate for young children ages 3 to 5 years and measure components of EF (working memory including visual spatial memory, inhibit/emotional control, shift/cognitive flexibility and speed of processing). Pilot data on the tasks were collected from a sample ( $n=229$ children) in North Carolina and Pennsylvania. Children ranged from 3.0 to 5.8 years of age and represented cross-age variation. The items on all six EF tasks exhibited strong longitudinal invariance across time. A second study demonstrated substantial improvements in children's performance on EF tasks across time. Recently designed preschool measures such as EF Touch can inform the development of similar, yet more multidimensional measures, appropriate for the infant-toddler years.

To attend to infant and toddler EF, not only during eligibility determination but also in program planning and implementation, El practitioners must be wellprepared in the qualitative aspects of EF competencies and developmental expectations throughout the infanttoddler period. This requires deep exploration of how EF can be expressed in the various authentic experiences occurring in a child's life within the family's cultural context. The scarcity of evaluation and assessment guidance described above can certainly hamper that. In one study, El practitioners reported discomfort in utilizing informed clinical opinion to make eligibility decisions when applied to traditional developmental domains [66]. Future research can examine effective professional development mechanisms to prepare emerging (i.e., students) and current El practitioners in infant-toddler EF, typical and concerning developmental variability in EF, and ways to assess via authentic observations converged with parental perspectives.

Armed with assessment data, El practitioners can design and implement interventions that consider ways to utilize the child's current EF competencies to learn individual functional outcomes, as well as promote the development of new EF competencies that contribute to the child's repertoire of approaches-to-learning. Strategies for promoting EF in infants and toddlers have been recommended (e.g., Center on the Developing Child [67]), however, evidence of their effectiveness in promoting overall child competence have not been tested, nor has there been any intervention research specifically with infants and toddlers with developmental delays or disabilities. Future research can examine the effectiveness of attending to the EF components of learning outcomes in early intervention.

\section{CONCLUSION}

EF as well as other approaches-to-learning are receiving significant attention from early childhood researchers. The conceptual model presented in this article acknowledges the important role of EF in complex cognitive development beginning in the early years of life. In this model, EF embodies the synergy of these multiple constructs including mastery motivation, self-regulation and self-determination. The emergence of the ability to engage in purposeful and goal-directed 
behavior are early manifestations of higher order reasoning in children and later adults [68]. Methods to implement the current developmental science evidence-base around approaches-to-learning into El assessment procedures has not yet occurred. This model can be used as a framework for examining a child's cognitive processes, motivational aspects, and regulatory approaches to inform referral, eligibility, and program planning decisions.

\section{REFERENCES}

[1] Diamond A. The early development of executive functions. In: Bialystock E, Craik FIM, Eds. The early development of executive functions. Lifespan cognition: Mechanisms of change. Oxford, England: Oxford University Press 2006; pp. 70-95. http://dx.doi.org/10.1093/acprof:oso/9780195169539.003.000 $\underline{6}$

[2] Shonkoff JP, Fisher PA. Rethinking evidence-based practice and two-generation programs to create the future of early childhood policy. Dev Psychopathol 2013; 25(4pt2): 1635-53. http://dx.doi.org/10.1017/S0954579413000813

[3] Individuals with Disabilities Education Improvement Act of 2004, 20 U.S.C. $\S 1400$ et seq. c2004 [cited 2015 Dec 13]. Available from: http://idea.ed.gov/

[4] Macy M, Bagnato $S$. The authentic alternative for assessment in early childhood intervention. In: Saklofske D, Reynolds C, Schwean V, editors. The Oxford handbook of child psychological assessment. New York: Oxford University Press 2013; pp. 671-82.

[5] Macy M, Bagnato SJ, Macy RS, Salaway J. Conventional tests and testing for early intervention eligibility: Is there an evidence-base? Infants Young Child 2015: 28(2): 182-204. http://dx.doi.org/10.1097//YC.0000000000000032

[6] Guralnick MJ. Why early intervention works: A systems perspective. Infants Young Child 2011; 24: 6-28. http://dx.doi.org/10.1097//YC.0b013e3182002cfe

[7] Collette F, Van der Linden M, Laureys S, et al. Exploring the unity and diversity of the neural substrates of executive functioning. Hum Brain Mapp 2005; 25(4): 409-23. http://dx.doi.org/10.1002/hbm.20118

[8] Aarnoudse-Moens CS, Smidts DP, Oosterlaan J, Duivenvoorden HJ, Weisglas-Kuperus N. Executive function in very preterm children at early school age. J Abnorm Child Psychol 2009; 37: 981-93.

http://dx.doi.org/10.1007/s10802-009-9327-z

[9] Best JR, Miller PH. A developmental perspective on executive function. Child Development 2010; 81(6): 1641-60. http://dx.doi.org/10.1111/j.1467-8624.2010.01499.x

[10] McCabe DP, Roediger III HL, McDaniel MA, Balota DA, Hambrick DZ. The relationship between working memory capacity and executive functioning: evidence for a common executive attention construct. Neuropsychology 2010; 24(2): 222.

http://dx.doi.org/10.1037/a0017619

[11] Raver CC, Blair C, Willoughby M. Poverty as a predictor of 4year-olds' executive function: New perspectives on models of differential susceptibility. Developmental Psychology 2013; 49(2): 292.

http://dx.doi.org/10.1037/a0028343

[12] Assel MA, Landry SH, Swank P, Smith KE, Steelman LM. Precursors to mathematical skills: Examining the roles of visual-spatial skills, executive processes, and parenting factors. Appl Dev Sci 2003; 7(1): 27-38.

http://dx.doi.org/10.1207/S1532480XADS0701 3
[13] Fletcher JM, Brookshire BL, Bohan TP, Beaver SR, Francis DJ. Cerebral white matter and cognition in hydrocephalic children. Arch Neurol 1992; 49: 818-24. http://dx.doi.org/10.1001/archneur.1992.00530320042010

[14] Lyon R. The need for conceptual and theoretical clarity in the study of attention, memory, and executive function. In: Lyon, GR, Krasnegor, N, editors. Attention, memory, and executive function. Baltimore, MD: Paul H. Brookes 1996; pp. 3-9.

[15] Denckla MB. A theory and model of executive function: A neuropsychological perspective. In: Lyon GR, Krasnegor N, Eds. Attention, memory, and executive function. Baltimore, MD: Paul H. Brookes 1996; pp. 263-278.

[16] Gioia GA, Espy KA, Isquith PK. Behavior Rating Inventory of Executive Function, Preschool Version (BRIEF-P). Odessa, FL: Psychological Assessment Resources 2002.

[17] Elton A, Gao W. Divergent task-dependent functional connectivity of executive control and salience networks. Cortex 2014; 51: 56-66. http://dx.doi.org/10.1016/j.cortex.2013.10.012

[18] National Research Council. From neurons to neighborhoods: The science of early childhood development. Washington, DC: National Academy Press 2000.

[19] Lawson KR, Ruff HA. Early attention and negative emotionality predict later cognitive and behavioral function. Int J Behav Dev 2004; 28: 157-65.

http://dx.doi.org/10.1080/01650250344000361

[20] Diamond A, Barnett WS, Thomas J, Munro S. Preschool program improves cognitive control. Science (New York, NY). 2007; 318(5855): 1387.

http://dx.doi.org/10.1126/science. 1151148

[21] Zelazo PD, Müller U, Frye D, Marcovitch S, Argitis G, Boseovski J, Chiang JK, Hongwanishkul D, Schuster BV, Sutherland A, Carlson SM. The development of executive function in early childhood. Monographs of the society for research in child development. 2003; i-151.

[22] Raver CC, Izard CE, Koop CB. Young children's emotional development and school readiness. Social policy report. 2003; 16(3): 3-19.

[23] Blasco PM. Social mastery motivation: Scaffolding opportunities for young children. In: Peterson C, Fox L, Blasco $P$, editors. Young exceptional children monograph series no. 10: early intervention for infants and toddlers and their families: Practices and outcomes. Missoula, MT: Division for Early Childhood 2008; pp. 93-104.

[24] Butterfield P, Martin C, Prairie A, Martin CA. Emotional connections: How relationships guide early learning. Washington, DC: Zero to Three 2004.

[25] Chevalier N. The development of executive function: Toward more optimal coordination of control with age. Child Dev Perspect 2015; 9(4): 239-44. http://dx.doi.org/10.1111/cdep.12138

[26] Avirett E, Maricle D. Executive function. In: Goldstein S, Naglieri J, editors. Encyclopedia of children, behavior and development. New York: Springer 2011; 616-618.

[27] Wiebe SA, Espy K, Charak D. Using confirmatory factor analysis to understand executive control in preschool children: I. Latent structure. Dev Psychol 2008; 44(2): 575-87. http://dx.doi.org/10.1037/0012-1649.44.2.575

[28] Bell MA, Adams SE. Comparable performance on looking and reaching versions of the A-not-B task at 8 months of age. Infant Behav Dev 1999; 22(2): 221-35. http://dx.doi.org/10.1016/S0163-6383(99)00010-7

[29] Bayley N. Bayley Scales of Infant and Toddler Development (BSID) III. San Antonio: TX: Psychological Corp 2005.

[30] Lowe J, Erickson SJ, MacLean P, Duvall SW. Early working memory and maternal communication in toddlers born very low birth weight. Acta Paediatr 2009; 98(4): 660-3. http://dx.doi.org/10.1111/j.1651-2227.2008.01211.x 
[31] Lowe J, MacLean PC, Shaffer ML, Watterberg K. Early working memory in children born with extremely low birth weight: Assessed by object permanence. J Child Neurol 2009; 24: 410-5.

http://dx.doi.org/10.1177/0883073808324533

[32] Isquith PK, Gioia GA, Espy KA. Executive function in preschool children: examination through everyday behavior. Dev Neuropsychol 2004: 26: 403-22. http://dx.doi.org/10.1207/s15326942dn26013

[33] Morgan GA, Harmon RJ, Maslin-Cole CA. Mastery motivation: Definition and measurement. Early Educ Dev 1990; 1: 318-39. http://dx.doi.org/10.1207/s15566935eed0105 1

[34] Busch-Rossnagel N, Morgan G. Introduction to section three: Overview and analysis. In: Barrett KC, Fox N, Morgan G, Fidler D, Daunhauer L, Eds. Handbook of self-regulatory processes in development: New directions and international perspectives. New York: Taylor and Francis 2013; pp. 247264. http://dx.doi.org/10.4324/9780203080719.ch12

[35] Morgan G, MacTurk R, Hrncir E. Mastery motivation: Overview, definitions, and conceptual issues. In: MacTurk $\mathrm{RH}$, Morgan GA, Eds. Mastery motivation: Origins, conceptualizations, and applications. Norwood, NJ: Ablex 1995; pp. 1-18.

[36] Barrett K, Morgan G, Maslin-Cole C. Three studies on the development of mastery motivation in infancy and toddlerhood. In: Messer D, Ed. Mastery motivation in early childhood: Development, measurement, and social processes. London: Routledge 1993; pp. 168-188.

[37] Messer D, McCarthy M, McQuiston S, MacTurk R, Yarrow L, Vietze $P$. Relation between mastery behavior in infancy and competence in early childhood. Dev Psychol 1986; 22: 36672.

\section{http://dx.doi.org/10.1037/0012-1649.22.3.366}

[38] Gilmore L, Cuskelly M, Purdie N. Mastery motivation: Stability and predictive validity from ages two to eight. Early Educ Dev 2003; 14: 411-24. http://dx.doi.org/10.1207/s15566935eed1404 2

[39] Morgan G, Wang J, Barrett K, Liao H, Wang P, Huang S, Jozsa K. The Revised Dimensions of Mastery Questionnaire (DMQ 18). Fort Collins, CO: Colorado State University; 2015 Nov 19 [cited 2015 Dec 13]. Available from: https://docs. google.com/viewer? $\mathrm{a}=\mathrm{v} \&$ pid=sites\&srcid=cmFtcy5jb2xvc3Rh dGUuZWR1fGdlb3JnZW1vcmdhbnxneDo0NmVmODE1Mml $4 \mathrm{MmI} 5 \mathrm{MmFI}$

[40] Division for Early Childhood (US). Recommended practices in early intervention/early childhood special education [Internet]. Los Angeles, CA: Division for Early Childhood; 2014 [cited August 13, 2014]. Available from: http://dec. membershipsoftware.org/files/Recommended\%20Practices/ DEC\%202014\%20Recommended\%20Practices.pdf

[41] Morgan GA, Wang J, Liao HF, Xu Q. Using the Dimensions of Mastery Questionnaire to assess mastery motivation and self-regulation: A cross national perspective. In: Barrett KC, Fox N, Morgan G, Fidler D, Daunhauer L, Eds. Handbook of self-regulatory processes in development: New directions and international perspectives. New York: Taylor and Francis 2013; pp. 305-336.

[42] Suen H, Logan CR, Neisworth J, Bagnato S. Parentprofessional congruence: Is it necessary? J Early Interv 1995; 19: 243-52. http://dx.doi.org/10.1177/105381519501900307

[43] Linder T. Transdisciplinary play-based assessment. $3^{\text {rd }}$ ed. Baltimore, MD: Paul H. Brookes 2008.

[44] Palmer S, Summers JA, Brotherson MJ, et al. Foundations for self-determination in early childhood: An inclusive model for children with disabilities. Topics Early Child Spec Educ 2013: 33(1): 38-47.

http://dx.doi.org/10.1177/0271121412445288
[45] Ursache A, Blair C, Stifter C, Voegtline K. Emotional reactivity and regulation in infancy interact to predict executive functioning in early childhood. Dev Psychol 2013; 49: $127-37$.

http://dx.doi.org/10.1037/a0027728

[46] Blair C, Raver S. School readiness and self-regulation: A developmental psychobiological approach. Annu Rev Psychol 2015; 66: 711-31. http://dx.doi.org/10.1146/annurev-psych-010814-015221

[47] Vallotton C, Ayoub C. Use your words: The role of language in the development of toddlers' self-regulation. Early Child Res Q 2011; 26: 169-81. http://dx.doi.org/10.1016/j.ecresq.2010.09.002

[48] Voress J, Maddox T. Developmental Assessment for Young Children - 2. San Antonio, TX: Pearson 2012.

[49] Dunn W. The Infant-Toddler Sensory Profile - 2. San Antonio, TX: Pearson 2014.

[50] Bagnato S, Neisworth J, Salvia J, Hunt F. Temperament and Atypical Behavior Scale (TABS). Baltimore, MD: Brookes Publishing 1999.

[51] Blasco PM, Falco RA, Munson LJ. Project SELF: Preparing professionals to facilitate self-determination. J Early Interv 2006; 29(1): 63-79.

http://dx.doi.org/10.1177/105381510602900105

[52] Erwin EJ, Brotherson MJ, Palmer SB, Cook CC, Weigel CJ, Summers JA. How to Promote Self-Determination for Young Children With Disabilities Evidenced-Based Strategies for Early Childhood Practitioners and Families. Young Exceptional Children 2009; 12(2): 27-37. http://dx.doi.org/10.1177/1096250608329611

[53] Erwin EJ, Brown F. Variables that contribute to selfdetermination in early childhood. TASH iVewsletter. 2000; 26(3): 8-10.

[54] Early Intervention Program for Infants and Toddlers with Disabilities Rule of 2011, 34 C.F.R. §303. c2011 [cited 2015 Dec 13]. Available from: http://idea.ed.gov/

[55] Lucas A, Shaw E. (2012). Informed clinical opinion (NECTAC Notes no. 28). Chapel Hill, NC: The University of North Carolina, FPG Child Development Institute, National Early Childhood Technical Assistance Center; 2012 Aug [cited 2015 Aug 4]. Available from http://www.nectac.org/ pdfs/ pubs/nnotes28.pdf

[56] Dannemiller JL. Do children's attention processes mediate the link between family predictors and school readiness? Society for Research in Child Development - SRCD 2003; 2003 April; Tampa, FL (US). (Joint Author: NICHD Early Child Care Research Network).

[57] Hebbeler K, Spiker D, Bailey D, et al. Early intervention for infants and toddlers with disabilities and their families: Participants, services, and outcomes. Final Report of the National Early Intervention Longitudinal Study (NEILS) [Internet]. Menlo Park, CA: SRI; 2007 January [cited 2015 May 27]. Available from https://www.sri.com/sites/default/ files/publications/neils_finalreport_200702.pdf

[58] U.S. Department of Education. Part C early intervention numbers and percentages 2013 [Internet data file]; 2014 [cited 2015 Dec 13]. Available from https://osep.grads360. org/\#communities/pdc/documents/7082

[59] Bagnato SJ, McKeating-Esterle E, Fevola A, Bortolamasi P, Neisworth JT. Valid use of clinical judgment (informed opinion) for early intervention eligibility: Evidence base and practice characteristics. Infants Young Child 2008; 21(4): 334-49. http://dx.doi.org/10.1097/01.IYC.0000336545.90744.b0

[60] Hebbeler K, Barton L. The need for data on child and family outcomes at the federal and state levels. In: Horn E, Peterson C, Fox L, editors. Young exceptional children monograph series no. 9: Linking curriculum to child and family outcomes. Missoula, MT: Division for Early Childhood 2007; pp. 1-15. 
[61] Busch-Rossnagel N. First do no harm: Culturally centered measurement for early intervention. In: Trimble J, Fisher C, editors. The handbook of ethical research with ethnocultural populations \& communities. Thousand Oaks, CA: Sage Publications, Inc. 2006; pp. 51-64. http://dx.doi.org/10.4135/9781412986168.n3

[62] McAfee O, Leong DJ. Assessing and guiding young learners' development and learning. Boston, MA: Allyn \& Bacon 2002.

[63] Bagnato S, McLean M, Macy M, Neisworth J. Identifying instructional targets for early childhood via authentic assessment: Alignment of professional standards and practice-based evidence. J Early Interv 2011; 33(4): 243-53. http://dx.doi.org/10.1177/1053815111427565

[64] Promoting positive outcomes for children with disabilities: Recommendations for curriculum, assessment, and program evaluation [Internet]. Missoula, MT: Division for Early Childhood; 2007 [2007] Available from http://dec. membershipsoftware.org/files/Position\%20Statement\%20and \%20Papers/Prmtg_Pos_Outcomes_Companion_Paper.pdf
[65] Willoughby MT, Pek J, Blair CB. Measuring executive function in early childhood: A focus on maximal reliability and the derivation of short forms. Psychological assessment. 2013; 25(2): 664 .

http://dx.doi.org/10.1037/a0031747

[66] Keilty B, LaRocco D, Casell F. Early interventionists' reports of authentic assessment methods through focus group research. Topics Early Child Spec Educ 2009; 28(4): 244-56. http://dx.doi.org/10.1177/0271121408327477

[67] Enhancing and practicing executive function skills with children from infancy to adolescence [Internet]. Center on the Developing Child [cited 2015 Jul 31]. Available from http://developingchild.harvard.edu/resources/enhancing-andpracticing-executive-function-skills-with-children-frominfancy-to-adolescence/

[68] Diamond A, Lee K. Interventions shown to aid executive function development in children 4 to 12 years old. Science 2011; 333(6045): 959-64.

http://dx.doi.org/10.1126/science.1204529

Received on 25-11-2015

Accepted on 01-12-2015

Published on 07-01-2016

\section{DOI: http://dx.doi.org/10.6000/2292-2598.2015.03.04.8}

(C) 2015 Keilty et al.; Licensee Lifescience Global.

This is an open access article licensed under the terms of the Creative Commons Attribution Non-Commercial License (http://creativecommons.org/licenses/by-nc/3.0/) which permits unrestricted, non-commercial use, distribution and reproduction in any medium, provided the work is properly cited. 